\title{
Development of Antimicrobial Conjugates and Evaluating its Antibacterial potential and Wound Healing ability
}

\author{
Deepak Tom Jose ${ }^{1}$, Sivagurunathan, $\mathrm{P}^{2}$, Aswini, $\mathrm{B}^{3}$, Dinesh, $\mathrm{MD}^{4}$ and $*$ Uma, $\mathrm{C}^{5}$ \\ ${ }^{1}$ Research scholar, Department of Microbiology, Annamalai University, Chidambaram- \\ 608002, Tamil Nadu, India, 8589989933, deepaktomjose@gmail.com \\ ${ }^{2}$ Assistant Professor, Department of Microbiology, Annamalai University, Chidambaram- \\ 608002, Tamil Nadu, India, 9940769774, sivaguru1981@ gmail.com \\ ${ }^{3}$ Research scholar, Department of Microbiology, Annamalai University, Chidambaram- \\ 608002, Tamil Nadu, India, 9487518666, iniyatamil1487@gmail.com
}

${ }^{4}$ Assistant Professor, Department of Microbiology, Pazhassiraja College, Wayanad-973579 Kerala, India, 9744061871, md.dineshmd45@gmail.com

${ }^{5}$ Assistant Professor, Department of Microbiology, Annamalai University, Chidambaram608002, Tamil Nadu, India, 9942370082, umasaravanan1 @ gmail.com

*Corresponding authors

${ }^{4}$ Assistant Professor, Department of Microbiology, Annamalai University, Chidambaram608002, Tamil Nadu, India,

9942370082

umasaravanan1@gmail.com 


\begin{abstract}
Antimicrobial peptides from Streptomyces sp. and marine fish (Carangoides malabaricus) were extracted and developed as conjugates in the present study. The objective was framed to analyze the ability of conjugate to retard the growth of test bacteria causing diabetic foot ulcers. Fibroblast cell adhesion on AMP conjugates coated mesh samples were recorded using microscopic studies with an aim of developing a novel tissue engineered wound dressing material. Thus developed tissue engineered materials were evaluated for its antibacterial potential against wound pathogens; and to assay the wound healing ability using a standard in vitro wound scratch method. Tissue engineered materials were developed using L929 fibroblast cells. L ${ }_{929}$ fibroblast cells attachment and its stage wise development on wound dressing mesh materials were microscopically observed. In vitro wound healing assay revealed that the developed conjugates (containing AMPs) exhibited cell migration and proliferation after $12^{\text {th }}$ hour of incubation indicating the wound healing abilities. The results showed that the developed tissue engineered wound dressing material has commercial interest in near future.
\end{abstract}

Keywords: Antimicrobial peptides, AMP conjugates, Diabetic foot, Tissue engineering, wound healing. 


\section{INTRODUCTION}

Skin is a cutaneous membrane acts as a barrier between the internal and external tissues. The cutaneous membrane is a bilayered membrane consists of top superficial epidermis and a connective dermis layer (Komal Vig et al., 2017). Many chronic wounds fail to heal, which can lead to amputations and mortality. Wound healing is natural process includes closure of wound, pain suppression and infection prevention (Mehmet Evren Okur et al., 2020). Wound healing also relies on the functions of stem cells; which stimulate the selfregeneration of wounded superficial epidermis and connective dermis layers (OwczarczykSaczonek et al., 2018). In deep injuries cases caused due to major accidents and severe burns, the wounds may be chronic. It was reported recently that, skin grafting is highly recommended in chronic cases (Rodrigues et al., 2018).

Skin grafting also termed as tissue engineered skin substitutes are considered as upcoming alternatives to existing wound treatment methods (Miyazaki et al., 2019). Tissueengineered skin substitute supplies significant donor-skin-graft to meet the deficiency of epidermal cells. Hence, it is reported to be a temporary protective layer covering the wound bed during the wound closure stages (Augustine, 2018). Different bioengineered and synthetic substitutes have been developed which provide the barrier function and protection against pathogenic bacteria and yeast, and promoting wound healing by tissue regeneration (Marino et al., 2014).

The success of tissue-engineered skin substitute depends on acceleration of certain biological process that takes place during wound healing process. The biological process includes, protecting damaged tissues from fluid loss and preventing contamination. The substitute also promotes cytokine release and growth factors at the wound site (Briquez et al., 2015). Some recent study on these tissue engineered wound dressing materials have been reported. Won et al., (2019) developed a potential dermal substitute using decellularized pig dermis and human dermal fibroblasts. Li et al., (2019) developed a natural polymer using oligoarginine mediated collagen/chitosan gel composite for cutaneous wound healing. In another study, electrospun polycaprolactone based scaffolds for wound healing and skin bioengineering applications was studied by Joseph et al., (2019). Different approaches have been adopted to develop engineered tissues, such as synthetic membranes for mono- or multilayered cultures and 3D matrices for full-thickness models (Grassner et al., 2019). 
Based on the synthetic membrane types for developing skin-grafts, a non-woven wound dressing mesh was used in the present research to develop one such tissue-engineered skin substitute under in vitro co-culturing methods. In our previous studies, the antimicrobial peptides (AMPs) were extracted from Carangoides malabaricus (Deepak Tom Jose et al., 2020); and the antibacterial activity of peptide coated wound healing mesh was evaluated against the test bacteria. In this research, the antimicrobial peptides (AMPs) from Streptomyces sp and Carangoides malabaricus were made as conjugates and coated onto the developed tissue-engineered wound mesh samples. The approach in this present research would pave way for developing a novel tissue engineered wound dressing with high commercial values in pharma and allied industries in near future.

\section{MATERIALS AND METHODS}

\section{Collection of test materials}

Marine fish, Carangoides malabaricus was collected from a marine source at Chidambaram, Tamil Nadu, India (Fig. 1). Streptomyces sp was collected from Microbiology Department of Annamalai University, Tamil Nadu. Non-woven wound dressing mesh was procured commercially from surgical shop, Chidambaram, Tamil Nadu, India (Fig. 2).

\section{Extraction of antimicrobial peptides from Carangoides malabaricus and Streptomyces} sp.

Antimicrobial peptides was extracted from Carangoides malabaricus and Streptomyces sp as per method described by Nieto Lozano et al., (1992) and Rajan and Kannabiran, (2014) respectively. The extraction of AMPs from Carangoides malabaricus was earlier presented in our previous publication (Deepak Tom Jose et al., 2020). Submerged fermentation method was used for the production and extraction of AMPs from Streptomyces sp. Ethyl acetate was used as solvent for the separation of AMPs from the production media. Both extracts were conjugated together and used for analyzing its antibacterial activity and wound healing ability.

\section{Conjugation of AMPs extracted from Carangoides malabaricus and Streptomyces sp}

Crude ethyl acetate extracts from Streptomyces production media and marine fish Carangoides malabaricus was developed as AMP conjugates by blending with each extracts. About $20 \mathrm{ml}$ each of the crude extracts were mixed together with the aid of a magnetic stirrer kept at $40-50^{\circ} \mathrm{C}$ (at 120rpm). Developed AMPs were confirmed from the evident protein settled down in the tubes as precipitates. The marine fish extracts were added onto the 
actinomycetes extracts at the rate of $10 \mathrm{ml}$ per minute. The extract was added constantly with continuous stirring conditions. The developed homogenous conjugates were stored at $4^{\circ} \mathrm{C}$ before processing for further studies (Sasmita et al., 2018).

\section{Antibacterial coating of wound dressing mesh}

Antibacterial coatings of wound dressing mesh (Fig. 3) was carried out using a standard dip-coating method as described by Gollwitzer et al., (2003). The detailed protocol of antibacterial coatings of wound dressing mesh using a carrier, poly-vinyl alcohol (PVA) was earlier presented in our previous publication (Deepak Tom Jose et al., 2020).

\section{Development of epidermal layer on the wound healing mesh using L929 $_{9}$ fibroblast cells}

Non-adhering wound dressing mesh samples was used in the study. L929dermal fibroblasts were cultured according to the standard culture method described by Houreld and Abrahamse, (2007). Briefly, cells were cultured in Dulbecco's modified Eagle's Medium (DMEM) supplemented with and $10 \%$ fetal calf serum, $1 \mathrm{mM}$ sodium pyruvate, $2 \mathrm{mM}$ Lglutamine, $0.1 \mathrm{mM}$ non-essential amino acids, $1 \%$ streptomycin and 0.2\% Amphotericin-B. The cells were cultured for 7 days in $75 \mathrm{~cm}^{2}$ cell culture flasks at $37^{\circ} \mathrm{C}$ and in humidified atmosphere containing $5 \% \mathrm{CO}_{2}$ atmosphere.

Wound dressing samples (coated with AMPs) were cut aseptically (20mm disc) and stabilized with a stainless-steel ring. Cultured fibroblasts were harvested through trypsinEDTA (Gibco) treatment and seeded at $2 \times 10^{4}$ cells $/ \mathrm{cm}^{2}$ on to the wound dressing samples by placing the material in a cell culture dish. Fibroblasts were incubated directly with the test specimen in complete DMEM (containing 1\% antibiotic - antimycotic solution and $10 \%$ fetal calf serum) for $24 \mathrm{~h}$ and the culturing process was carried out using rotary cell culture system. During the incubation period, cell morphology and cell proliferation on the wound dressing samples were recorded.

\section{Investigating L929 fibroblast cell proliferation and adhesion on the wound healing mesh using FESEM analysis}

Rotary cell culture system was used for the proliferation of fibroblast at a revolution rate $15-20$ rotation per min. The proliferation was carried out at $37^{\circ} \mathrm{C}$ and in humidified atmosphere containing $5 \% \mathrm{CO}_{2}$ atmosphere. The increase in the cell number and attachment on the surface and interstices of the fibers were recorded at $0^{\text {th }} \mathrm{hr}, 6^{\text {th }} \mathrm{hr}, 12^{\text {th }} \mathrm{hr}$ and $24^{\text {th }} \mathrm{hr}$. These developed wound dressing materials shall be used to promote diabetic wound healing in diabetic ulcers and other chronic wounds. Developed materials with attached fibroblasts 
were visualized after thawing under a field emission scanning electron microscope (Houreld and Abrahamse, 2007).

Determining the antibacterial activity of AMP conjugate coated wound healing material

Cell developed wound healing mesh coated with AMP conjugate were analyzed for antibacterial activity using a standard disc diffusion method as described by El-Rehewy et al., 2009). The antibacterial activity of AMP coated mesh was earlier presented in our previous publication (Deepak Tom Jose et al., 2020). Briefly, the mesh was cut (disc shaped-20mm) and placed over MHA plates pre-seeded with test organisms. Mesh without AMP conjugate was used as control samples. Zone around the AMP conjugate-coated mesh was measured after 24 hours of incubation and the results were presented as mean \pm standard deviation

Analyzing the wound healing ability of developed AMP conjugates using in vitro wound scratch assay

L929 mouse fibroblast cells grown in 24 well plates at a density $\left(1 \times 10^{5}\right.$ cells per $\left.\mathrm{ml}\right)$ with $\sim 80 \%$ confluence was taken for the analysis. A small linear scratch was created in the confluent monolayer by gently scraping with sterile cell scrapper as per the method of Liang et al. (2007). After creating a scratch on L929 mouse fibroblast cell lines, the cell migration, cell proliferation and wound closure was measured for the selected concentrate $(100 \mu \mathrm{g})$ of AMP conjugates at different time periods $\left(0^{\text {th }}\right.$ hour, $12^{\text {th }}$ hour and $24^{\text {th }}$ hour $)$. Migration of cells between the scratch site and the distance traversed by cells migrating into the denuded area which emphasize the self-healing was observed using Phase contrast microscope for each time period.

\section{RESULTS AND DISCUSSION}

\section{L929 fibroblast cell proliferation and adhesion}

L929 fibroblast cells attachment and its stage wise development on wound dressing mesh materials were microscopically observed. Inverted microscopic images showing the extent of cell attachment and proliferation of $\mathrm{L}_{929}$ cells on the fibres and interstices were noted from $0^{\text {th }} \mathrm{hr}$ to $24^{\text {th }} \mathrm{hr}$. The increase in the cell number and attachment on the surface and interstices of the fibres were observed at $0^{\text {th }} \mathrm{hr}, 6^{\text {th }} \mathrm{hr}, 12^{\text {th }} \mathrm{hr}$ and $24^{\text {th }} \mathrm{hr}$. No growth was observed on $0^{\text {th }}$ hr (Fig. 5A). Partial cell growth was observed on $6^{\text {th }}$ hr (Fig. 5B). Cell attachment was found to be evident on $12^{\text {th }} \mathrm{hr}$ (Fig. 5C) and proliferated cell covering the entire surface and interstices of the fibres was observed at $24^{\text {th }}$ hr (Fig. 5D). With increasing cultivation period of time, fibroblasts showed a preference for aligning in parallel to one 
another. The present findings indicate multiple layers of cells on mesh were resulted from intense matrix production by fibroblasts in the developed conditions.

\section{Antibacterial activity of AMPs conjugate coated mesh samples}

Antibacterial activity of cell developed wound healing mesh coated with AMP conjugates were analyzed against different test bacteria. The antibacterial activity was expressed based on the inhibitory zones measured around each conjugate coated mesh samples.

Escherichia coli and Staphylococcus aureus exhibited inhibitory zones of $32.1 \pm 0.56$ $\mathrm{mm}$ and $31.3 \pm 1.25 \mathrm{~mm}$ for the coated mesh samples. Klebsiella pneumoniae and Pseudomonas aeruginosa exhibited the inhibitory zones of $26.3 \pm 1.04 \mathrm{~mm}$ and $29.3 \pm 0.56$ $\mathrm{mm}$ against their respective coated samples. Acinetobacter baumannii showed significantly $30.1 \pm 1.25 \mathrm{~mm}$ of inhibitory zones for the test samples (Table-1 and Fig. 4). The obtained results revealed that the antimicrobial conjugates increased the therapeutic effect against the test organisms. The mode of action of AMP conjugates was reported to penetrate the pyramidal wall of bacteria followed by disrupting the cytoplasmic contents; and hence adhesion of pathogen at the wound site was prevented.

\section{Wound healing ability of developed AMP conjugates using in vitro wound scratch assay}

In vitro wound healing assays have commonly been applied to measure cell migration, cell proliferation and wound closure in response to stimulation with specific agents. In this study, the AMP conjugates used for the cell adhesion studies was determined for its ability to improve wound healing by acting directly on $\mathrm{L}_{929}$ mouse fibroblast cells.

After creating a scratch on L $_{929}$ mouse fibroblast cell lines, the cell migration, cell proliferation and wound closure was measured for a known concentration $(100 \mu \mathrm{g})$ of AMP conjugates at three different time periods $\left(0^{\text {th }}\right.$ hour, $12^{\text {th }}$ hour and $24^{\text {th }}$ hour$)$. Fig. 6 corresponding to self-wound healing ability of the developed AMP conjugates showed that, at $0^{\text {th }}$ hour, no cell migration and proliferation was observed for the known concentrate $(100 \mu \mathrm{g})$ including control (Distilled water). At $12^{\text {th }}$ hour, positive cell migration and cell proliferation was observed when compared to the control sample. After 24hours, more cell proliferation was evident indicating the wound closure. In Fig. 6, the control showed a little more cell proliferation than the treatment group after $24^{\text {th }}$ hour. This was due to a small delay in the healing process of the AMP conjugate samples on the developing L $_{929}$ cell lines when compared to the control. The reason for this little difference was illustrated from the research 
article of Peplow and Chattrejee, (2013). The researchers explained that many growth factors and cytokines enhanced migration of keratinocytes in vitro. This migration of keratinocytes may vary from one sample to another depending on these above factors. However, in our present study $100 \%$ wound closure was clearly evident in both the control group and the sample groups after the incubation study period. The results revealed that AMP conjugates could be used as wound healing agents for any biomedical cases like diabetic foot ulcers, boil wounds, bur wounds, accidental cuts/wounds, etc.

In vitro scratch assay could be recorded as an appropriate and inexpensive method for the wound healing potential of herbal composite used in the present research.

Similar in vitro wound scratch assay method was recorded from the literature survey. Srinivasa Rao Bolla et al. (2019) recently investigated the wound healing capacity of Aristolochia saccata leaf extract by using In vitro wound scratch assay, where proliferative and migratory capabilities of test compounds could be monitored through microscopy studies. L929 fibroblast cell line was used for the assay. Scratch assay showed $34.05 \%$, $70.00 \%, 93.52 \%$ wound closure at $12 \mathrm{hrs}, 24 \mathrm{hrs}$ and $48 \mathrm{hrs}$ of incubation respectively. These results were similar compared to positive control which showed $37.60,56.41$ and $99.05 \%$ of wound closure. As there was similar wound healing abilities were noted for many antimicrobial compounds from the literature survey on L $_{929}$ mouse fibroblast cell lines, it was proved that the developed AMP conjugates could be used for the development of novel tissue engineered wound healing materials.

\section{CONCLUSION}

Antimicrobial peptides extracted from Streptomyces sp and Carangoides malabaricus were developed as conjugate. The conjugate was mixed with PVA and coated with wound dressing mesh samples. The cell adhesion assay, antibacterial activity and in vitro wound healing assay of developed tissue engineered wound dressing mesh revealed a need for such a novel product for treating complicated diabetic foot ulcer infective cases. Based on the obtained wound healing ability of developed conjugates, it can be concluded that the developed tissue engineered wound dressing material could be useful to treat diabetic wounds. The fibroblast migration and proliferation of cells could able to favour in increasing the levels of cytokines, growth factors and keratinocytes at the wound site which results in effective wound healing in diabetic wounds. The results showed that the developed tissue 
engineered wound dressing has commercial interest in pharmaceuticals companies for the manufacturing of such materials in near future with different types of drugs coating on it.

\section{CONFLICT OF INTEREST}

Authors declare no conflict of interest 


\section{REFERENCES}

Augustine R. Skin bioprinting: A novel approach for creating artificial skin from synthetic and natural building blocks. Prog Biomater. 2018;7:77-92.

Briquez PS, Hubbell JA, Martino MM. Extracellular Matrix-Inspired Growth Factor Delivery Systems for Skin Wound Healing. Adv Wound Care 2015;4:479-489.

Deepak Tom Jose, Uma C, Sivagurunathan P, Aswini B, and Dinesh MD. Extraction and antibacterial evaluation of marine AMPs against diabetic wound pathogens. J App Pharm Sci. 2020;10(11):87-92.

El-Rehewy MK, El-Feky MA, Hassan MA, Abolella HA, Abolyosr A, El-Baky RM and Gad GF. In vitro Efficacy of Ureteral Catheters Impregnated with Ciprofloxacin, N-acetyl cysteine and their Combinations on Microbial Adherence. Clin Med, 2009;3:1-8.

Grassner L, Marhold F, Yousif M, Grillhosl A, Ungersboeck K, Schulz J and Strowitzki M. Experiences with a temporary synthetic skin substitute after decompressive craniectomy: A retrospective two-center analysis. Acta Neurochir. 2019;161:493-499.

Gollwitzer H, Ibrahim K, Meyer H, Mittelmeier WR, Busch, R and Stemberger, A. Antibacterial poly (D, L-lactic acid) coating of medical implants using a biodegradable drug delivery technology, Journal of Antimicrobial Chemotherapy, 2003;51:585-591.

Houreld $\mathrm{N}$ and Abrahamse $\mathrm{H}$. In vitro exposure of wounded diabetic fibroblast cells to a helium-neon laser at 5 and $16 \mathrm{~J} / \mathrm{cm}^{2}$. Photomed Laser Surg, 2007;25:78-84.

Joseph B, Augustine R, Kalarikkal N, Thomas S, Seantier B and Grohens Y. Recent advances in electrospun polycaprolactone based scaffolds for wound healing and skin bioengineering applications. Mater Today Commun, 2019;19:319-335.

Komal Vig, Atul Chaudhari, Shweta Tripathi, Saurabh Dixit, Rajnish Sahu, Shreekumar Pillai, Vida A. Dennis and Shree R. Singh. Advances in skin regeneration using Tissue Engineering. Int J Mol Sci. 2017;18:2-19.

Li M, Han M, Sun Y, Hua Y, Chen $G$ and Zhang L. Oligoarginine mediated collagen/chitosan gel composite for cutaneous wound healing. Int J Biol Macromol, 2019;122:1120-1127.

Liang CC, Park AY, Guan JL. In vitro scratch assay: a convenient and inexpensive method for analysis of cell migration in vitro. Nat Protoc, 2007; 2(2):329-33. 
Marino D, Luginbühl J, Scola S, Meuli M and Reichmann E. Bioengineering dermoepidermal skin grafts with blood and lymphatic capillaries. Sci Transl Med. 2014;6:221-224.

Mehmet Evren Okur, Ioannis D. Karantas, Zeynep Senyigit, Neslihan Ustundag Okur and Panoraia I. Siafaka. Recent trends on wound management: New therapeutic choices based on polymeric carriers. Asian J Pharm Sci, 2020;15(6):661-684.

Melanie Rodrigues, Nina Kosaric, Clark A. Bonham, and Geoffrey C. Gurtner. Wound Healing: A Cellular perspective. Physiol Rev, 2019;99:665-706.

Miyazaki H, Tsunoi Y, Akagi T, Sato S, Akashi M and Saitoh D. A novel strategy to engineer pre-vascularized 3-dimensional skin substitutes to achieve efficient, functional engraftment. Sci Rep. 2019;9:779-783.

Nieto Lozano JC, Meyer JN, Sletten K, Pelaz C, Nes, IF. Purification and amino acid sequence of a bacteriocin produced by Pediococcus acidilactici. Journal of General Microbiology, 1992;138:1985-1990.

Owczarczyk-Saczonek A, Krajewska-Włodarczyk M, Kruszewska A, Banasiak L, Placek W, Maksymowicz W and Wojtkiewicz J. Therapeutic potential of stem cells in follicle regeneration. Stem Cells Int. 2018;1:234-239.

Peplow PV and Chatterjee MP. A review of the influence of growth factors and cytokines in in vitro human keratinocyte migration. Cytokin. 2013; 62(1):1-21.

Rajan BM and Kannabiran K. Extraction and Identification of Antibacterial Secondary Metabolites from Marine Streptomyces sp. VITBRK2. Int J Mol Cell Med. 2014; 3(3):130137.

Sasmita M, Ankita A, Abhijit M. Antibacterial activity of Antimicrobial peptide (AMP) Grafted polystyrene surface. Advances in Polymer Science and Technology, 2018;2:39-46.

Srinivasa Rao Bolla, Abeer Mohammed Al-Subaie, Reem Yousuf Al-Jindan, In vitro wound healing potency of methanolic leaf extract of Aristolochia saccata is possibly mediated by its stimulatory effect on collagen-1 expression, Heliyon, 2019; 5(5):641-648.

Vladimir Smrkolj, T Bailey, Tomaz Velnar. The Wound Healing Process: An Overview of the Cellular and Molecular Mechanisms. J Int Med Res, 2009;37(5):1528-1542. 
Won JY, Lee MH, Kim MJ, Min KH, Ahn G, Han JS, Jin S, Yun WS and Shim, JH. A potential dermal substitute using decellularized dermis extracellular matrix derived bio-ink. Artif Cells Nanomed Biotechnol, 2019;47:644-649. 


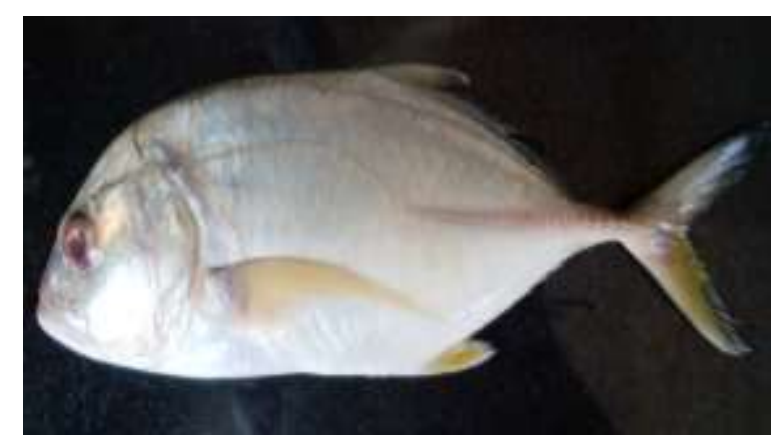

Fig. 1: Carangoides malabaricus fish for extraction of AMP

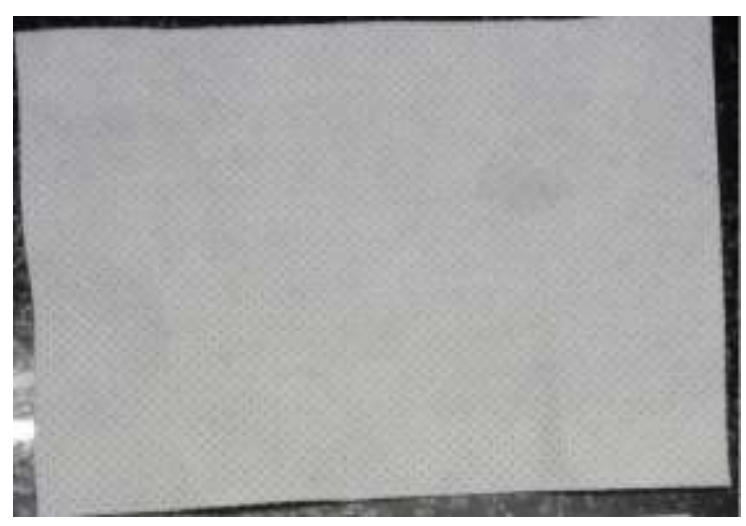

Fig. 2: Non-woven wound dressing mesh used in the study

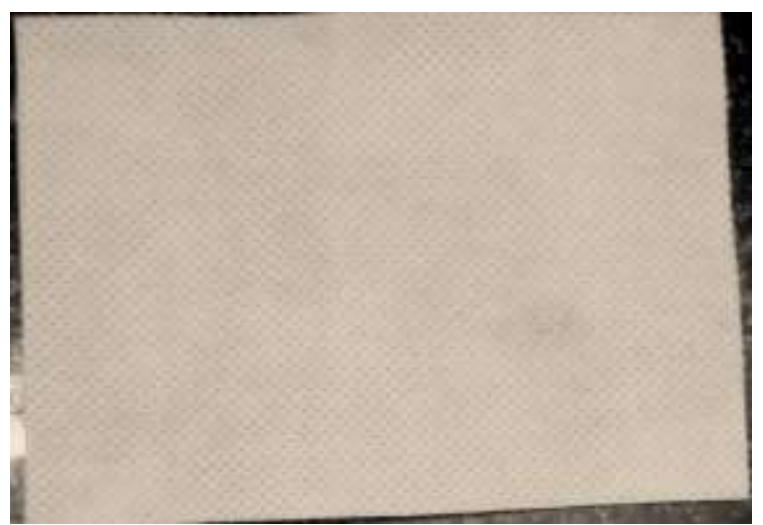

Fig. 3: Wound dressing mesh coated with AMP conjugates and PVA 


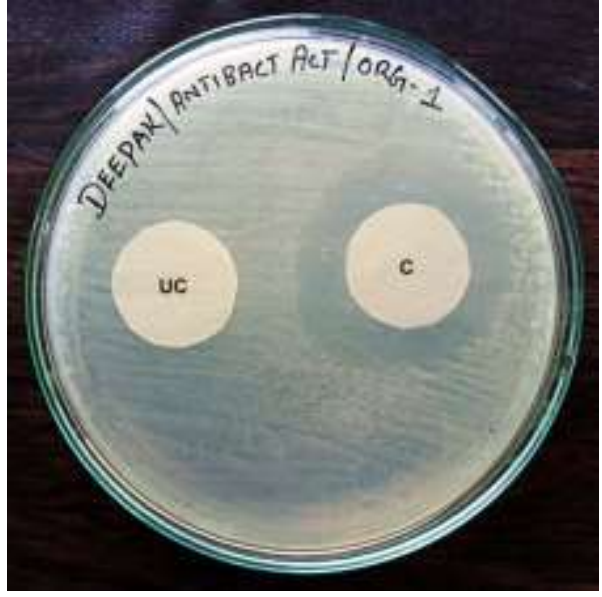

Escherichia coli

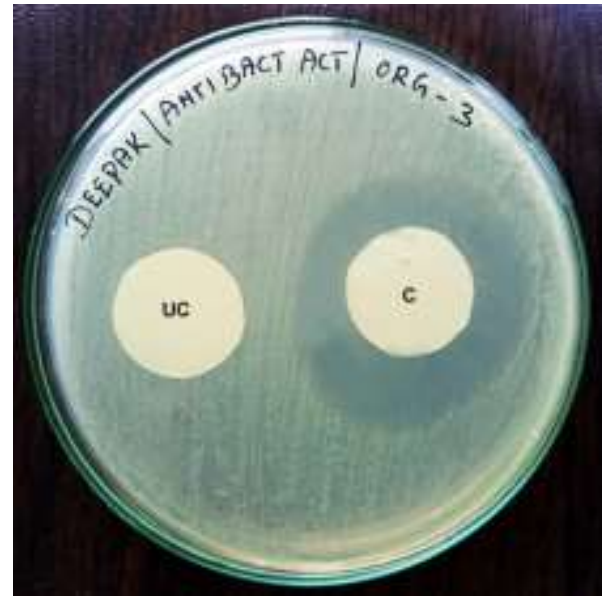

Klebsiella pneumoniae

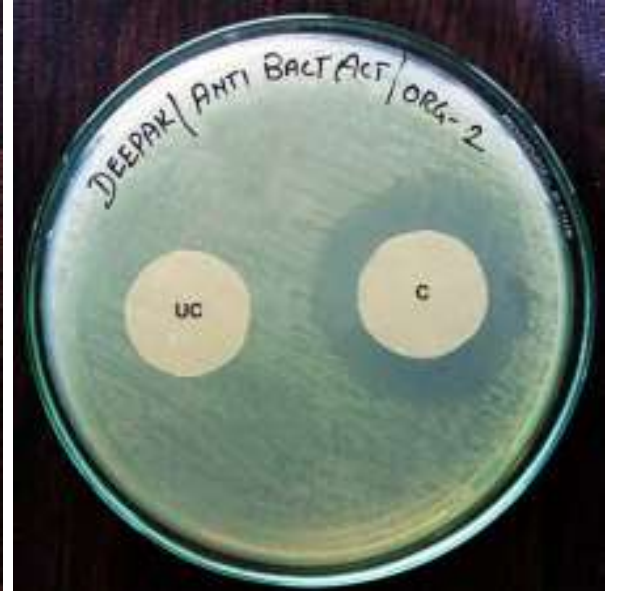

Staphylococcus aureus

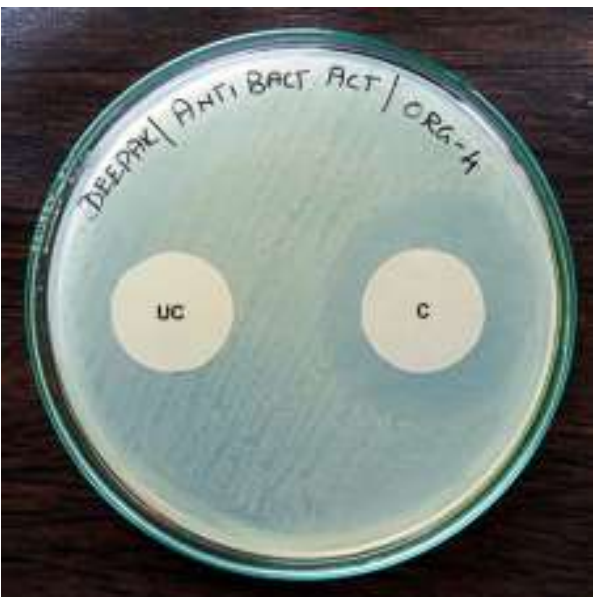

Pseudomonas aeruginosa

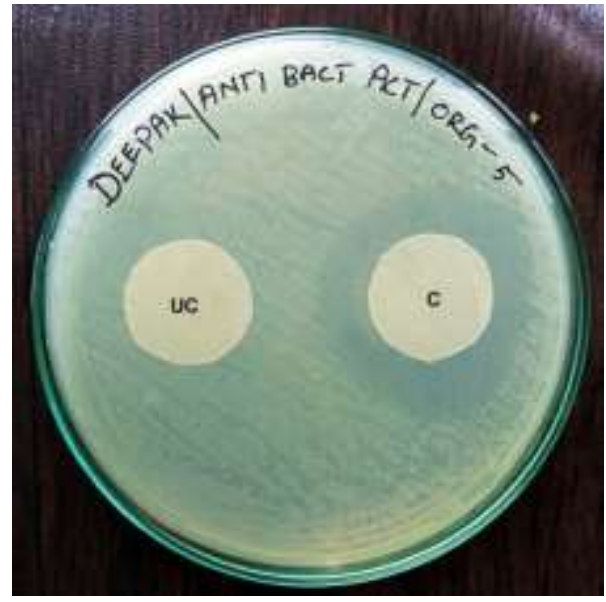

Acinetobacter baumannii

Fig. 4: Antibacterial activity of AMPs + PVA coated mesh samples

(UC: Uncoated C: Coated) 


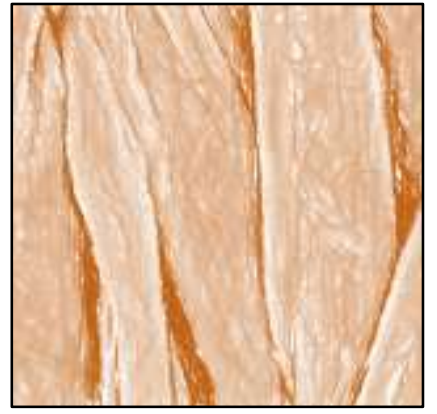

A

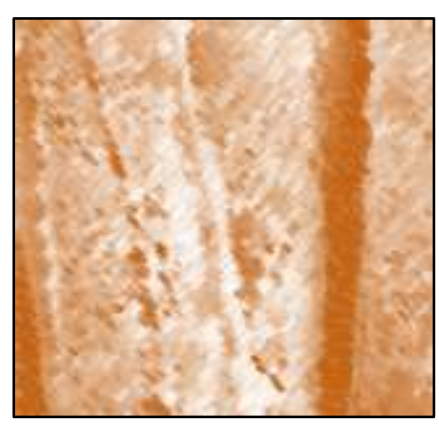

C

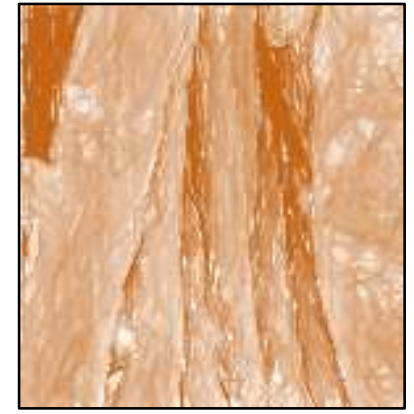

B

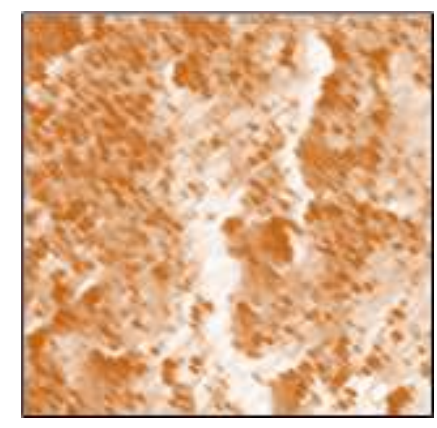

D

Fig. 5: L929 fibroblast cell proliferation and adhesion

A: L929fibroblast cell development on wound dressing mesh at $0^{\text {th }}$ hour (No cell growth)

B: L929fibroblast cell development on wound dressing mesh after $6^{\text {th }}$ hour (Partial cell growth)

C: L929fibroblast cell development on wound dressing mesh after $12^{\text {th }}$ hour (Cell attachment evident)

D: L929fibroblast cell development on wound dressing mesh after $24^{\text {th }}$ hour (Proliferated cell covering the entire surface and interstices of the fibre) 


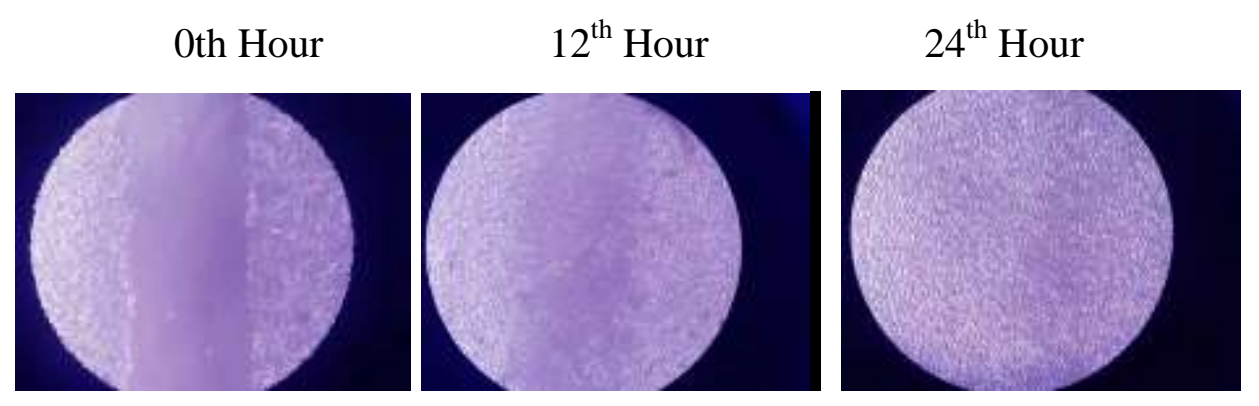

Fig. 6A: Control (Distilled water)
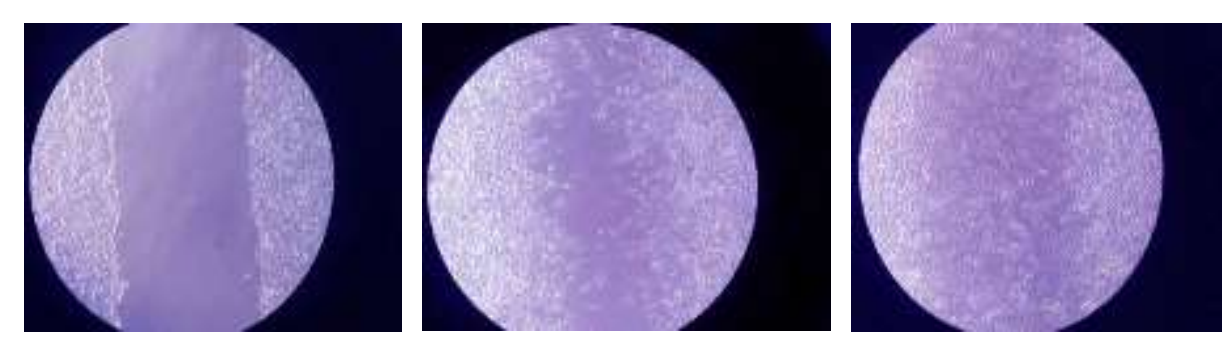

Fig. 6B: Sample $(100 \mu \mathrm{g})$

Fig. 6: Self-wound healing scratch assay: In vitro Wound Scratch Assay

Table-1: Qualitative antibacterial activity of AMPs + PVA coated materials

\begin{tabular}{|c|c|c|}
\hline \multirow{2}{*}{ S. No } & \multirow{2}{*}{ Test organism } & Zone of inhibition (mm) \\
\cline { 3 - 3 } & & AMPs + PVA coated ${ }^{*}$ \\
\hline 1 & Escherichia coli & $32.1 \pm 0.56$ \\
\hline 2 & Staphylococcus aureus & $31.3 \pm 1.25$ \\
\hline 3 & Klebsiella pneumoniae & $26.3 \pm 1.04$ \\
\hline 4 & Pseudomonas aeruginosa & $29.3 \pm 0.56$ \\
\hline 5 & Acinetobacter baumannii & $30.1 \pm 1.25$ \\
\hline
\end{tabular}

